Schulich School of Law, Dalhousie University

Schulich Law Scholars

Using Strategic Environmental Assessments to Guide Oil and Gas Exploration Decisions: Applying Lessons Learned from Atlantic Canada to the Beaufort Sea

Meinhard Doelle 


\title{
Using Strategic Environmental Assessments to Guide Oil and Gas Exploration Decisions: Applying Lessons Learned from Atlantic Canada to the Beaufort Sea
}

\author{
Meinhard Doelle, Nigel Bankes and Louie Porta
}

\begin{abstract}
The Macondo oil spill in the Gulf of Mexico has spurred renewed global interest in the regulation of offshore oil and gas exploration, particularly in deepwater areas. At the same time, many jurisdictions are experimenting with strategic environmental assessment (SEA) processes to fill gaps in more traditional project-based decision-making processes. This article explores the potential of SEA to enhance decision making for exploration in deepwater environments. It does so by examining the experience with SEAs on the east coast of Canada, and applying the lessons learned to the Beaufort Sea. By looking at the issue in two very different environments, we can draw lessons that may also apply to deepwater exploration elsewhere.
\end{abstract}

\section{INTRODUCTION}

The twenty-first century has seen renewed interest in developing Arctic oil and gas reserves. ${ }^{1}$ The marine waters of the Arctic Ocean prospectively hold 13\%, 30\% and $20 \%$ of undiscovered global oil, natural gas and gas liquid reserves. ${ }^{2}$ The development of Arctic marine petroleum resources has become a priority for the five coastal Arctic nations: Canada, Denmark, Norway, Russia and the United States. Simultaneously, multinational hydrocarbon companies view the Arctic as the last major oil and gas frontier. Sustainable Arctic oil and gas exploration and development requires a preemptive, strategic decision-making process that can effectively guide economic considerations in step with environmental risks.

Historically, hydrocarbon development efforts focused on land or shallow water hydrocarbon potential. Since 2008, the industry has shifted its attention to the deepwater areas of the Beaufort Sea - a region that to date

\footnotetext{
${ }^{1}$ Northern Canada is estimated to contain a third of Canada's remaining potential for conventional oil and natural gas. See <http:// www.aadnc-aandc.gc.ca/eng/1100100037301>.

${ }^{2}$ D.W. Houseknecht, K.J. Bird and C.P. Garrity, Assessment of Undiscovered Petroleum Resources of the Arctic Alaska Petroleum Province (US Geological Survey, 2012).
}

has experienced limited exploration and no development. ${ }^{3}$ In the wake of the huge 2009 Macondo oil spill in the Gulf of Mexico, Canada's National Energy Board (NEB) initiated a public review of offshore drilling in the Canadian Arctic to ensure the regulatory system was prepared to handle the unique challenges. ${ }^{4}$ There was no similar examination of the adequacy and appropriateness of Canada's Arctic oil and gas rights issuance process. In this article, we argue that a key weakness in the current procedure is the failure of the government to apply state of the art strategic environmental assessments (SEAs) as part of deciding where and when to open new areas to potential oil and gas drilling activities.

In the past two decades, SEAs have emerged as an important complement to project-based environmental assessments (EAs) and other planning tools. The interest in SEAs arises from an understanding of the limitation of project-based EA processes, which are not well suited to dealing with a consideration of alternatives, cumulative effects and broader policy issues. Furthermore, project-based EAs are undertaken at a time when important decisions and commitments have already been made. SEAs have been used internationally as part of making decisions on opening new areas to potential oil and gas drilling activities, and they have also been used on the east coast of Canada to inform the first phases of the oil and gas rights issuance process (industry nominations, more formal government calls for nominations and calls for bids). ${ }^{5}$ SEAs attempt to outline, integrate, refine and mitigate regional-scale concerns related to ecologically sensitive areas, multisectoral ocean use and cumulative effects in advance of project-based EAs. They also have the potential to consider the need, purpose and rationale of a proposed

\footnotetext{
${ }^{3}$ Aboriginal Affairs and Northern Development Canada (AAND), Northern Oil And Gas Annual Report (AAND, 2011), at 9.

${ }^{4}$ National Energy Board (NEB), The Past is Always Present: Review of Offshore Drilling in the Canadian Arctic (NEB, 2011), at 3.

${ }^{5}$ See, e.g., C. Fidler and B. Noble, 'Advancing Strategic Environmental Assessment in the Offshore Oil and Gas Sector: Lessons from Norway, Canada and the United Kingdom', 34 Environmental Impact Assessment Review (2012), 12.
} 
development and alternatives to offshore oil and gas development before specific projects are proposed. In other words, SEAs are well suited to asking what societal needs are being met with this type of development, and whether there are better ways to meet those needs. This is particularly significant in Canada since neither calls for nominations nor the call for bids will trigger an EA under the Canadian Environmental Assessment Act (CEAA). ${ }^{6}$

Other jurisdictions also routinely conduct SEAs before opening up new areas for oil and gas activities, ${ }^{7}$ including other Arctic States (such as the United States, Norway and Denmark/Greenland) with offshore hydrocarbon potential. In addition, the Arctic Council's Offshore Oil and Gas Guidelines support the use of SEAs as part of best practice in the development of oil and gas resources. ${ }^{8}$ More generally, European countries have considerable experience with the use of SEA as a decision-making tool to address some of the shortcomings of more traditional project-based EA processes. Many European countries, including Arctic States, are party to the Kiev Protocol on Strategic Environmental Assessment. ${ }^{9}$ Article 4 of the Protocol requires parties to conduct an SEA for 'plans and programmes which are prepared for ... [inter alia the] energy industry ... and which set the framework for future development consent' for certain listed projects, including offshore hydrocarbon production projects. ${ }^{10}$

SEAs have been used as a key ingredient of the oil and gas rights issuance process for exploration in the waters of Nova Scotia and Newfoundland-Labrador since

${ }^{6}$ SC 1992, c. 37 . The CEAA has been replaced by the Canadian Environmental Assessment Act 2012, SC 2012, c. 19, but the new Act does not change this fundamental point.

${ }^{7}$ J. Dagg, et al., Comparing Deepwater Drilling Regulatory Regimes of the Canadian Arctic, the US, the UK, Greenland and Norway (Pembina Institute, 2011).

${ }^{8}$ Arctic Council, Arctic Offshore Oil and Gas Guidelines (2009), found at: <http://www.arctic-council.org/index.php/en/about/documents/ category/62-pame>. The Arctic Council recommends the use of SEA 'on a regional basis to determine the potential environmental impacts of human activity including opening areas for oil and gas'. Ibid., at 17. The Guidelines articulate three key reasons for conducting SEAs. First, since an SEA occurs early in the process it can and should integrate environmental concerns into the first stages of decision making. Second, an SEA has, by definition, a wide scope and thus sets the stage for the more specific environmental impact assessments that will follow as hydrocarbon development unfolds. Third, individual strategic environmental assessments form part of an ongoing strategic environmental assessment process, insofar as they continuously update baseline scientific knowledge of the region under investigation. Ibid.

${ }^{9}$ UNECE Protocol on Strategic Environmental Assessment to the Convention on Environmental Impact Assessment in a Transboundary Context (Kiev, 21 May 2003; in force 11 July 2010) ('Kiev Protocol'). As of September 2012 there were 25 parties to the Kiev Protocol. The Arctic States that are party are: Denmark, Finland, Norway and Sweden. Denmark's ratification, however, does not extend to the Faroe Islands and Greenland.

${ }^{10} \mathrm{Ibid}$., Articles 4.1 and 4.2, and Annex I, item 15.
2002. Since then, the Canada-Newfoundland and Labrador Offshore Petroleum Board (C-NLOPB) and the Canada-Nova Scotia Offshore Petroleum Board (C-NSOPB) have conducted eight SEAs. As this article discusses, the two offshore boards used SEAs to achieve five objectives:

(1) to inform decisions related to the issuance of exploration licenses in the study area;

(2) to understand the interaction between expected exploration activities and the receiving environment, including its current use;

(3) to minimize environmental and safety disasters;

(4) to identify sensitive environmental areas which require special mitigation protocols; and

(5) to identify areas where development should be avoided. ${ }^{11}$

There are some important legal and jurisdictional differences between Canada's Arctic and east coast which need to be taken into account in developing and applying SEAs, but none of these differences undermine the fundamental point that a state of the art SEA process which meets international standards is a key part of the responsible development of offshore oil and gas resources. Some of these key jurisdictional differences include the unique constitutional status of the three northern territories under Canadian law (and therefore the role played by the Department of Aboriginal Affairs and Northern Development), the important role played by land claim agreements and related institutions in northern Canada.

The article proceeds as follows. It first describes how the federal oil and gas leasing regimes operate in three different parts of Canada: Nunavut, the Northwest Territories and associated offshore areas, ${ }^{12}$ the areas offshore of Newfoundland and Labrador; and the areas offshore of Nova Scotia. This section shows that while the relevant legislation is silent with respect to SEAs, the example of the east coast boards demonstrates that

\footnotetext{
${ }^{11}$ There are, of course, some differences between the SEA processes of the two boards. Most notably, the Nova Scotia Board does not deal with development, nor does it explicitly consider whether an area should be avoided for development. Its focus is exclusively on exploration. The Newfoundland Board does give some consideration to development, but it is not clear how this information affects decisions by the board.

12 Following devolution of oil and gas rights and legislative responsibility to Yukon in November 1998, Yukon now has its own oil and gas regime (the Yukon Oil and Gas Act, RSY 2002, c. 162). Note that the Yukon government recently decided not to proceed with a disposition following expressions of interest by industry in blocks of land in the Whitehorse Trough. The government noted that it had been surprised by these expressions of interest and concluded that concerns and questions were raised that required further study thus, somewhat ironically, confirming the importance of making decisions to open a new area only after a strategic assessment that involves input from the public. See Yukon Government News Release, 'Government of Yukon Announces Decision on Oil and Gas Postings' (12 April 2012), found at: <http://www.gov.yk.ca/news/2011/files/12-064.pdf>.
} 
it is possible to integrate SEA procedures within the current disposition rules. The following sections examine the form of SEA that should be put in place for the Canadian Beaufort Sea. To that end, the article draws on SEA literature to provide a statement of principles of good practice. The article next describes the SEA practice of the east coast boards and offers some brief comparative commentary on relevant SEA experiences in the United Kingdom and Norway. The ensuing section critiques the practice to date in light of the SEA principles. The final part of the article draws on this experience and analysis to outline how an effective SEA process for the Canadian Beaufort Sea might be integrated into the current oil and gas exploration and leasing regime as well as the two land claim agreements which touch on the Beaufort Sea: the Inuvialuit Final Agreement and the Nunavut Land Claim Agreement. This section will also illustrate how an SEA could build on the proposed oil and gas research initiative, the Beaufort Regional Environmental Assessment.

\section{OIL AND GAS DISPOSITION SCHEMES FOR FEDERAL LANDS IN CANADA: THE CANADA PETROLEUM RESOURCES ACT AND OFFSHORE ACCORDS}

The three oil and gas leasing regimes that cover the Northwest Territories, Nunavut, the Arctic offshore, and the marine areas offshore of Nova Scotia and Newfoundland and Labrador all have the same starting point, which is the disposition scheme described in the Canada Petroleum Resources Act (CPRA). ${ }^{13}$ On the east coast, the respective Accords ${ }^{14}$ between Canada and the two provincial governments ${ }^{15}$ resulted in additional provisions being grafted onto the basic scheme described by the CPRA, largely to provide a role for joint federal-provincial decision making through the two offshore boards: the C-NSOPB ${ }^{16}$ and the C-NLOPB. ${ }^{17}$ The Accords were implemented by mirror legislation adopted by the Canadian parliament and the

\footnotetext{
${ }^{13}$ RSC 1985 , c. 36 (2nd Supp) ('CPRA').

${ }^{14}$ The Atlantic Accord: Memorandum of Agreement between the Government of Canada and the Government of Newfoundland and Labrador on Offshore Oil and Gas Resources Management and Revenue Sharing, 11 February 1985, found at: <http://www.servicenl.gov.nl.ca/ printer/publications/aa_mou.pdf;; Canada-Nova Scotia Offshore Petroleum Resources Accord (1986), found at: <http://gov.ns.ca/ energy/resources/RA/offshore/1986-Canada-NS-OffshorePetroleum-Resource-Accord.pdfs.

${ }^{15}$ The Accords were negotiated to allow the provincial governments a co-management role with respect to the offshore areas adjacent to their coasts, notwithstanding a series of Supreme Court decisions that confirmed that these offshore areas were all beyond the territory of the respective provinces and therefore subject to federal jurisdiction.

${ }^{16}<$ http://www.cnsopb.ns.ca/>

$17<$ http://www.cnlopb.nl.ca/>
}

provincial legislature: the Canada-Nova Scotia Offshore Petroleum Resources Accord Implementation Act $(\mathrm{CNS})^{18}$ and the Canada- Newfoundland Atlantic Accord Implementation Act (CNL). ${ }^{19}$ In what follows we focus on the CPRA regime and then describe how the east coast regimes track or differ from that of the CPRA.

The CPRA provides for three forms of tenure: an exploration licence, a significant discovery licence and a production licence. In the normal course of events, a licensee progresses from the exploration licenses, via the significant discovery licence, to the production licence. ${ }^{20}$ Both the exploration licence and the significant discovery licence grant the licensee the exclusive right to drill wells and to obtain a production licence. ${ }^{21}$ An exploration licence has a maximum duration of nine years. ${ }^{22} \mathrm{~A}$ licensee can only hold onto the lands beyond the term of the exploration licence if it makes a significant or commercial discovery ${ }^{23}$ during the term of the exploration licence. ${ }^{24} \mathrm{~A}$ significant discovery licence has an indefinite duration and is effectively a holding licence which allows a licensee to hold on to a discovery pending, for example, the development of appropriate infrastructure (e.g., a pipeline). ${ }^{25} \mathrm{~A}$ production licence grants the licensee the exclusive right to produce and title to the oil and gas produced. This licence is issued for a 25-year term, which is renewable if petroleum is still being produced commercially at the end of the initial term. ${ }^{26}$

This article focuses on the first step in this three-step tenure scheme: the procedure for issuing an explora-

18 The federal legislation is SC 1988, c. 28 ('CNS'); the provincial legislation is SNS 1987, c. 3.

${ }^{19}$ The federal legislation is SC 1987 , c. 3 ('CNL'); the provincial legislation is RSNL 1990, c. 2 .

${ }^{20}$ It is possible for the Crown to issue either a significant discovery licence or a production licence as part of a call for bids if there is a declaration of significant or commercial discovery in place for those lands.

${ }^{21}$ CPRA, n. 13 above, section 22 (on exploration licences) and section 29 (on significant discovery licences).

22 Ibid., section 26.

${ }^{23}$ There is a formal process for making a declaration of significant discovery and a declaration of a commercial discovery. Both are defined terms under the Act. Under the CPRA, these declarations are made by the NEB. On the east coast, these decision are made by the two offshore boards. There has been some litigation on the declaration process. See, in particular, Petro-Canada v. CanadaNewfoundland Offshore Petroleum Board (1995), 127 DLR $\left(4^{\text {th }}\right) 483$ and Mobil Oil Canada Ltd v. Canada-Newfoundland Offshore Petroleum Board (1994), 1 SCR 202. In addition, the two east coast boards have offered guidance on these issues. See Joint Guidelines Regarding Applications for Significant or Commercial Discovery Declarations and Amendments (May 2003), found at: <http://www.cnlopb.nl.ca/ pdfs/guidelines/sda_0503.pdf> ('Joint Guidelines').

${ }^{24}$ Lands revert to the status of Crown reserve lands if they are not subject to a declaration. CPRA, n. 13 above, sections 26.6 and 32.4 . ${ }^{25}$ The CPRA does not prescribe a term, but section 33 (ibid.) does authorize the Minister to issue a drilling order to persons holding an interest in the significant discovery

26 Ibid., section 41. 
tion licence. This comprises a two-step procedure that involves: a 'call for nominations' and a 'call for bids'. ${ }^{27}$ The CPRA addresses the subject of calls for bids, but it does not expressly refer to calls for nominations. ${ }^{28}$ The same is true of the two east coast statutes, although C-NSOPB has issued a set of detailed guidelines on the issuance of exploration licences.

A 'call for nominations' is a procedure by which the government assesses whether industry has any interest in bidding on particular lands. It is in effect a call upon industry to nominate particular lands that a company might wish to see listed in a call for bids. Calls for nominations remind industry to be aware of relevant land claim agreements and also draw attention to the species listed in the Species at Risk Act, ${ }^{29}$ as well as any relevant land use plans with which developers may have to conform. Calls for nominations may be geographically targeted. Thus, governments may only ask for nominations in particular areas (or may exclude other areas).

A 'call for bids' is a formal document issued by the Department of Aboriginal Affairs and Northern Development in which it calls upon industry to bid on particular blocks of land. The Act requires the Minister to use a single bidding variable in selecting the successful bid. ${ }^{30}$ This is typically a work bid (i.e., the amount of work such as seismic or wells to which the company is prepared to commit). There is no pre-qualification of applicants.

The crucial point for present purposes is that the call for nominations and the call for bids start a process which, if carried through to completion, will see a developer acquire an exploration licence and perhaps (successively or not) a significant discovery licence or a production licence. Neither the call for nominations nor the call for bids triggers an environmental assessment under the terms of the Canadian Environmental Assessment Act because there is no project activity at this stage in the process. ${ }^{31}$ Similarly, the CPRA and the east coast statutes are completely silent on the need for an SEA.

Not all oil and gas exploration activities require an exclusive tenure under the CPRA or the east coast statutes. In particular, while a party requires an exploration licence, a significant discovery licence or a pro-

\footnotetext{
27 Note that the Nova Scotia Board does not have a formal call for nominations; operators may nominate lands at any time, but nominations are reviewed by the board on a certain date each year.

${ }^{28}$ But see CPRA, n. 13 above, section 14.2, which provides that: 'Any request received by the Minister to make a call for bids in relation to particular frontier lands shall be considered by the Minister in selecting the frontier lands to be specified in a call for bids.'

${ }^{29}$ SC 2002, c. 29.

${ }^{30}$ CPRA, n. 13 above, section14.3(g).

${ }^{31}$ See N. Bankes and P. Rowbotham, 'The Oil and Gas Industry: Some Current Problems in Environmental Law', in: G. Thompson et al. (eds.), Environmental Law and Business in Canada (Canada Law Book/Aurora, 1993), 543.
}

duction licence in order to drill a well, they do not require one of these forms of licence in order to conduct seismic exploration. Instead, such an activity requires an authorization under the Canada Oil and Gas Operations Act (COGOA). ${ }^{32}$ Since a seismic operation - unlike the mere issuance of a licence - is a physical activity, a request for an authorization will trigger an environmental assessment under the CEAA.

Seismic programmes vary in intensity and purpose. Some seismic activity is conducted by the Geological Survey of Canada and similar science-based institutions to obtain a better understanding of regional geology and structure. Other seismic activity, so-called 'speculative' or 'spec' seismic activity, is conducted (as the name implies), by companies who run seismic surveys in anticipation of calls for bids or nominations in order to sell the results to oil and gas exploration companies. And finally, the successful bidder on an exploration block will likely both commit to (under the terms of the exploration licence) and want to (i.e., for reasons of self-interest) run additional seismic to determine priority drilling locations for any wells it plans or is required to drill.

The legislation is completely silent with respect to consultation with aboriginal peoples, although all three statutes contain an aboriginal rights savings clause or non-derogation clause. ${ }^{33}$ However, consultation obligations may be imposed by relevant land claim agreements ${ }^{34}$ or by the Canadian Constitution as interpreted by the relevant case-law. ${ }^{35}$

There are several key differences between the CPRA and the east coast statutes. First, the latter provide for the joint or co-management of offshore lands. ${ }^{36}$ There is no co-management of lands covered by the CPRA within Nunavut and the Northwest Territories. Instead, the operating assumption, at least in relation to land areas, is that federal oil and gas management will, at

\footnotetext{
32 RCS 1985, c. O-5

33 CPRA, n. 13 above, section 3; CNS, n. 18 above, section 50; CNL, n. 19 above, section 48.

${ }^{34}$ For example Article 27.1.2 of the 1993 Nunavut Land Claims Agreement, found at: <http://www.aadnc-aandc.gc.ca/eng/ $1100100030601 / 1100100030602>$, provides that: 'Prior to the initial exercise of rights in respect of exploration, development or production of petroleum on Crown lands in the Nunavut Settlement Area, and in order to prepare a benefits plan for the approval of the appropriate regulatory authority, the proponent shall consult the [Designated Inuit Organization], and Government shall consult the [Designated Inuit Organization], in respect to those matters listed in Schedule 27-1.' 35 See, in particular, Beckman v. Little Salmon/Carmacks First Nation (2010), SCC 53 ('Beckman'), which is the authority for the proposition that the terms of a land claim agreement do not exhaust the Crown's duty to consult.

36 CNS, n. 18 above, Part I, Joint Management; CNL, n. 19 above, Part I, Joint Management.
} 
some time in the future, be devolved to the territorial governments. ${ }^{37}$

Second, in furtherance of the idea of joint management, the two east coast statutes have established offshore boards and recognize the concept of a 'fundamental decision', which is an important decision to be made by the board that prima facie requires the concurrence of both the federal and provincial ministers (subject to some exceptions). ${ }^{38}$ There is no equivalent to the boards under the CPRA, although the National Energy Board does have a role in assessing significant and commercial discoveries and is also responsible for administering much of the COGOA.

Third, in the case of the lands subject to the CPRA there is a clear separation between the property and regulatory functions of government. Thus, the CPRA is very much concerned with managing the Crown's oil and gas property interests while the regulation of oil and gas activities falls under the COGOA. The east coast statutes deal with both issues in the same piece of legislation.

Fourth, the east coast statutes, consistent with the two Accords, provide for resource revenue sharing. ${ }^{39}$ There are no similar arrangements under the CPRA, although revenue sharing arrangements may be put in place as part of the devolution arrangements ${ }^{40}$ and may also be prescribed by the terms of land claim agreements. ${ }^{41}$

Fifth, there are also differences in practice between the rights issuance processes of the Department of Aboriginal Affairs and Northern Development and those of the two offshore aforementioned boards. Some of these differences are quite significant. For example, east coast boards have been much more active in issuing guidelines to industry than Northern Oil and Gas Canada or the National Energy Board.42 Moreover, the CPRA covers a much broader variety of lands than the East Coast statutes. All wells on the east coast that fall under the jurisdiction of the boards are offshore wells. By contrast, the CPRA covers both land and marine areas and thus some of the activities carried out under the CPRA would look very similar to conventional oil and gas operations in Northern Alberta or British Columbia.

\footnotetext{
${ }^{37}$ The model here is Yukon (see n. 12 above). Yukon also obtained jurisdiction over the so-called 'adjoining area': the immediate inshore area close to the Yukon coast.

${ }^{38}$ CNS, n. 18 above, section 2; and CNL, n. 19 above, section 2.

${ }^{39} \mathrm{CNL}$, n. 19 above, Part IV.

${ }^{40}$ For Yukon see, Yukon Government News Release, 'Yukon Welcomes PM's Commitment to Improve Resource Revenue Sharing Agreement' (29 August 2011), found at: <http://www.gov.yk.ca/news/ 2011/files/11-132.pdfs.

${ }^{41}$ See, e.g., the 1993 Nunavut Land Claims Agreement, n. 34 above, Article 25.

${ }^{42}$ Examples include the Joint Guidelines, n. 23 above and the C-NSOPB, Guidelines on the Issuance of Exploration Licences (January 2012), found at: <http://www.cnsopb.ns.ca/sites/default/ files/pdfs/final_guidelines_on_issuance_of_el_.pdfs.
}

Furthermore, the east coast boards have, as will be discussed below, followed the practice of conducting SEAs before calling for bids in a new area. There is no similar consistent practice for lands subject to the CPRA, although in some cases the Government of Canada has experimented with integrated planning processes such as the Beaufort Sea Strategic Regional Plan of Action ${ }^{43}$ and the Beaufort Regional Environmental Assessment.

\section{SEA PRINCIPLES OF GOOD PRACTICE}

SEAs are not new. They have been carried out in many jurisdictions - most notably the European Union and by parties to the Kiev Protocol. ${ }^{44}$ In Canada, there have been federal cabinet directives on SEAs in place for over two decades. Some provinces also allow for EAs of policies, plans and programmes. Furthermore, several SEAs have been carried out in Canada without any specific legal authorization or requirement. ${ }^{45}$

The term 'SEA' means different things to different people, and is practiced very differently across jurisdictions. Some definitions, such as the one in the current federal cabinet directive, use the term primarily in the context of major decisions by the executive branch of government. Others view SEA as an overriding concept that covers all EAs that go beyond individual projects. ${ }^{46}$

Perhaps the most familiar form of SEA is the assessment of a proposed government policy, plan or programme. This form of SEA is a reactive process that seeks to identify potential environmental concerns associated with proposed government action before

${ }^{43}$ Fisheries and Oceans Canada, 'Announcement of an Integrated Oceans Management Plan for the Beaufort Sea' (27 August 2010), found at: <http://www.dfo-mpo.gc.ca/media/back-fiche/2010/hqac43a-eng.htm>.

44 Kiev Protocol, n. 9 above; see also United Nations Economic Commission for Europe (UNECE), Resource Manual to Support Application of the Protocol on Strategic Environmental Assessment (United Nations, 2012).

${ }^{45}$ Because most jurisdictions do not require SEAs to be carried out, when they are identified as useful in a particular context SEAs are often designed on an ad hoc basis. For examples, see B.F. Noble and J. Bronson, Models of Strategic Environmental Assessment in Canada (Canadian Environmental Assessment Agency, 2007); $\mathrm{H}$. Benevides et al., Law and Policy Options for Strategic Environmental Assessment in Canada (October 2009), found at: <http://papers. ssrn.com/sol3/papers.cfm?abstract id=1660403>; and R. Gibson et al., 'Strengthening Strategic Environmental Assessment in Canada: An Evaluation of Three Basic Options', 20:3 Journal of Environmental Law and Practice (2010), 175.

${ }^{46}$ For an assessment of the federal cabinet directive on SEA, see S. Hazel and $\mathrm{H}$. Benevides, 'Federal Strategic Environmental Assessment: Toward a Legal Framework', 7:3 Journal of Environmental Law and Practice (1997), 349. See also B.F. Noble and J. Harriman Gunn, 'Strategic Impact Assessment', in: K.S. Hanna (ed.), Environmental Impact Assessment: Practice and Participation (Oxford University Press, 2005), 93. 
government approval is granted. However, SEAs can take many other forms. Some focus on specific industry sectors (e.g., offshore wind or tidal power production) or a particular type of activity (e.g., energy, shale gas exploration and hydraulic fracturing, aquaculture and fishing). Others focus on a range of activities in a given region. SEAs can also be used to develop a new policy, plan or programme, or to assess existing policies.

Dalal-Clayton and Sadler consider a number of definitions of SEA in their 2005 book on international experience with SEAs. ${ }^{47}$ They note that early definitions of SEA were closely linked to project assessments. More recent definitions have tended to take a broader perspective by including environmental, economic and social considerations. Furthermore, SEA is increasingly seen as a tool for the proactive development of policies, plans and programmes, rather than a reactive review. ${ }^{48}$

SEAs can be used in a variety of contexts, with different needs and outcomes. Nevertheless, there appears to be general agreement on the basic steps and principles that should guide SEA processes. The procedural steps proposed for SEAs tend to be similar to project EAs and include the following: process selection or design; continuous public engagement; broad scoping; information gathering; review and analysis; documentation of results; decision making; and follow-up.

Dalal-Clayton and Sadler offer a mix of general and SEA-specific principles to guide the development of SEAs. ${ }^{49}$ Noble and Harriman Gunn similarly draw on the EA literature when concluding that SEA should: focus on basic objectives and how to achieve them; identify desired future outcomes and consider fully alternative ways of achieving these outcomes; focus on objectives; be proactive; be integrated; take a broad approach; and be tiered. ${ }^{50}$ These are all principles utilized in the literature on project-specific EAs. ${ }^{51}$

The following nine principles of good SEA practice are proposed based on our review of SEA literature. Their relevance in the offshore oil and gas exploration context is then explored in the following section.

\section{The SEA should be applied early and proactively}

SEAs should be triggered before important policy and project decisions are made, and no such decisions should be made during the course of an SEA. There should be clear rules as to when an SEA should be

\footnotetext{
${ }^{47}$ B. Dalal-Clayton and B. Sadler, Strategic Environmental Assessment (Earthscan, 2005).

${ }^{48}$ Ibid., at 9-17.

49 Ibid., Box 2.4, at 15.

${ }^{50}$ See B.F. Noble and J. Harriman Gunn, n. 46 above.

${ }^{51}$ See M. Doelle, The Federal Environmental Assessment Process: A

Guide and Critique (LexisNexis Butterworths, 2008), at 29.

applied. There should be a clear statement of the purpose of an SEA, including the decisions it is intended to inform.

2. The SEA should be integrated at a substantive level by incorporating biophysical (or 'ecological'), social and economic aspects

The SEA process should pay particular attention to issues that have been difficult to deal with at the project level, such as broader policy considerations, cumulative effects, alternative means of achieving societal objectives and intergenerational considerations.

\section{The SEA should take into account its place within the other 'tiers' or levels of assessment}

A policy decision on whether, when and under what conditions to approve a certain type of activity in a given study area would be expected to directly influence future decisions in relation to particular project activities. Assessments of lower tier initiatives may influence improvements in a higher tier. For instance, a previous project-based EA on exploratory seismic activity may provide useful information for an SEA on exploratory drilling. An SEA on exploratory drilling may in turn inform integrated management planning. Improved assessments at all levels, as well as the practical benefit that the overall assessment process is 'streamlined', are among the benefits of 'tiering'. The process or terms of reference should establish a clear link between the SEA outcomes and future higher and lower tier decisions.

\section{The process should be guided by a legislative, regu- latory or policy context}

The legal context should confirm the need for consistency in legislation and regulations while providing opportunities for improvement through ongoing strengthening and clarification of the guidance. It should establish the standard of assessment that must be met in legislation. It should include clear delineation of assessment roles and responsibilities in legislation, with mechanisms to ensure credible independence of assessment review, impartial administration and adequate time and resources in legislation, regulations and guidance as appropriate. By including these elements, the legal context improves transparency, opportunity and provides incentives to participate.

5. The process should be sufficiently flexible to fit the particular circumstances of individual SEAs and be carried out in an effective, efficient and fair manner

The process should be adjustable to fit the needs of a particular SEA. The process design should consider the overall context, including the subject matter of the SEA, the scope, the decisions to be informed, the existing decision-making context; and should identify who is in 
charge of the process. The process needs to have the combination of flexibility and guidance necessary to identify the appropriate scope of the SEA in light of the decision that is to be informed. In turn, the party in charge of the process must be carefully selected to be impartial in light of the purpose and scope of the SEA and the decisions to be informed.

6. The process should be transparent and include opportunities for active public involvement throughout

Transparency is a necessary but not sufficient condition for public engagement. SEAs require enhanced efforts to encourage public participation. SEAs are only as useful as they are successful in engaging those with a stake in the outcome. The success of public engagement therefore ultimately has to be measured in terms of the result, and not just the effort to engage. Given their longer term impact on decision making compared to project-specific EAs, there needs to be a clear statement as to how (and for how long) the SEA will inform future decisions.

\section{The SEA process should include effective incentives} to ensure that it is adhered to; that government, industry and public participants are motivated to learn from the results of the process; and that decision makers allow the results to inform future decisions

One of the lessons from project-specific EA is that it is possible to mandate government decision makers to follow an EA process, but it is difficult to force an unmotivated, unwilling decision maker to implement the process so as to maximize its influence on future decisions and to make better decisions based on the results of the process. This means that an SEA should be designed to motivate decision makers to learn from the process and to use the results to make better decisions.

\section{The SEA should be followed up in terms of actual performance as well as actual effects}

The SEA should require that actual performance be compared with predictions, and that appropriate steps are taken in response to the results of the follow up in terms of improving: future decision making under the particular SEA; the development of future SEAs and resulting policy decisions; and the SEA process itself.

\section{There must be political commitment to put in place and implement a SEA regime and to use its results}

Much of the momentum for implementing an effective SEA process will only be realized when decision makers are shown the benefits of such a regime. Key decision makers should be participants in the design, establishment and implementation of the regime. By participating in the process, decision makers are more likely to see the benefits of following the recommendations, to understand the subtleties of the conclusions reached, and to appreciate the risk of deviating from the results in terms of community and stakeholder support for future government decisions..$^{52}$

Some of the recommendations we make here have also been articulated by others. For example, oil and gas planning and research is well underway in the Canadian Beaufort Sea, and in 2004 the Inuvialuit Game Council initiated a joint federal-Inuvialuit-industry oil and gas planning process, which culminated in the Beaufort Sea Strategic Regional Plan of Action..$^{53}$ The Council specifically recommended an SEA for the Canadian Beaufort Sea to ensure a coordinated and integrated regional approach towards EAs and cumulative effects associated with future offshore oil and gas developments. ${ }^{54}$

These nine principles of good SEA practice are all drawn from our own update of a literature review that was an integral part of the 2009 report on SEA commissioned by the CEAA. ${ }^{55}$ We add one additional principle here to the effect that any SEA process that is adopted for offshore oil and gas issues in the Arctic must reflect and be consistent with not only the terms of relevant land claim agreements, but also with their overall intent. We return to this point below.

In addition to the SEA literature, experience with SEAs elsewhere also provides important context for the design of a SEA for the Beaufort Sea. The next section therefore considers the experience on the east coast of Canada in some detail. This is followed by a brief comparative assessment of SEA experience in the offshore oil and gas context in Norway and the United Kingdom.

\section{SEA EXPERIENCE IN THE OFFSHORE OIL AND GAS CONTEXT}

We have described the procedure by which companies acquire offshore oil and gas rights through exploration licences, noting that in some cases spec seismic may occur before any exploration licence is issued. The decision to issue an exploration licence does not require action under CEAA, although seismic activities and drilling operations may require an EA. There is no requirement under the offshore board legislation for an SEA to inform exploration licence decisions. However,

\footnotetext{
52 See H. Benevides et al., n. 45 above.

${ }^{53}$ Beaufort Sea Strategic Regional Plan of Action (April 2008), found at: <http://www.bsstrpa.ca/pdf/bsstrpa/BSStRPA\%20RPA\%20March 2009.pdf $>$.

54 Ibid., at 2.

55 See H. Benevides et al., n. 45 above.
} 
both the C-NSOPB and C-NLOPB began using SEAs before opening up new areas under a call for bids in the early 200os, around the same time that stakeholders debated whether exploration activities should be subject to a screening or comprehensive study under the CEAA..$^{66}$

In 2005, the C-NSOPB sought policy advice from both levels of government on the need to conduct SEAs prior to a call for bids in an area. In response, the federal Minister directed the board to undertake SEAs prior to issuing licenses, unless the area in question had previously been studied in the context of a comprehensive review. The province gave similar direction. The conclusion reached was that decisions on exploration are covered by the federal cabinet directive on SEA. ${ }^{57}$ At the project level, federal regulators settled on requiring only a screening-level assessment for seismic projects and exploration wells. The provincial governments were reportedly supportive of this approach. ${ }^{58}$

The mandate of both boards is to regulate offshore oil and gas development in a manner consistent with statutory obligations dealing with issues such as environmental protection and safety. This is important context. Neither board has a mandate to consider broader policy issues, such as how to resolve potentially competing visions for the future of the offshore area under their jurisdiction.

\section{EXPLORATION SEAs: NOVA SCOTIA ${ }^{59}$}

The C-NSOPB first started carrying out SEAs to inform decisions on exploration licenses in 2003 with an SEA for an area immediatelysurrounding the Gully east of Sable Island. ${ }^{60}$ In addition, it participated in a joint SEA with the C-NLOPB for the Laurentian Sub-basin - an area that was partly within the jurisdiction of each of the two boards. Since these two early experiments with

\footnotetext{
${ }^{56}$ The end result of this process was a change to the comprehensive study regulation that exempted exploration activity from a comprehensive study under the CEAA. Canadian Environmental Assessment Agency, 'Federal Minister Stéphane Dion Announces Changes to the Environmental Assessment of Offshore Oil and Gas Exploratory Drilling Project' (17 November 2005), found at: <http://www. ceaa-acee.gc.ca/default.asp?lang=En\&xml=06DF5879-EEB1-4C21BDB1-480BC47C038E>.

${ }^{57}$ See C. Fidler and B. Noble, n. 5 above.

${ }^{58}$ Personal communication with Eric Theriault at C-NSOPB, February 2012.

${ }^{59}$ For information on SEAs carried out by the C-NSOPB, see <http:// www.cnsopb.ns.ca/environment/environmental-assessments/seapublic-registry>.

${ }^{60} \mathrm{C}-\mathrm{NSOPB}$, Strategic Environmental Assessment of Potential Exploration Rights Issuance for the Eastern Sable Island Bank, Western Banquereau Bank, the Gully Trough and the Eastern Scotian Slope (June 2003), found at: <http://www.cnsopb.ns.ca/pdfs/ GullySEAJune03.pdf>.
}

SEAs, the C-NSOPB has carried out two more exploration assessments: one for the Misaine Bank area east off Cape Breton in 2005, and one for the Southwestern Scotian Slope off mainland Nova Scotia in 2011. ${ }^{61}$

The focus of all exploration SEAs carried out by the C-NSOPB has been on potential interactions between expected exploration activity and the receiving environment, including its current uses. All four SEAs were intended to inform decisions related to the issuance of exploration licenses in the study area, rather than broader policy issues such as whether oil and gas production is an appropriate activity in the study area or whether the resources should be explored now or saved for future use. ${ }^{62}$

The scope of all four SEAs is also similar. In line with the objective of informing decisions about issuing exploration licenses, SEAs focus on the biophysical environment, existing human activities in the area, activities expected to be involved in exploration, possible interactions with the biophysical environment and existing activities, special risks and sensitivities identified, and special mitigation needs or areas to be avoided.

The process has varied somewhat, but the basic elements have been the same. First, C-NSOPB chooses the area for the SEA based on potential interest in exploration activities and production potential of the area. Typically, the trigger for the SEA appears to be a call for bids in a given offshore area. Areas that have been previously studied in the context of a comprehensive study or panel review under a project-specific EA have so far been excluded from SEAs. Boundaries for the study area generally coincide with parcels generated for the bidding process. The main variant in the process has been the time taken and the level of public engagement.

The first public step in the SEA process has been the preparation of a draft scoping document by an outside consultant who carries out the major components of the SEA. C-NSOPB staff take responsibility for the process, while outside consultants assume responsibility for

\footnotetext{
${ }^{61}$ See CEF Consultants, Strategic Environmental Assessment of the Misaine Bank Area (December 2005), found at: <http://www. cnsopb.ns.ca/pdfs/MisaineSEAFinalRep.pdf> ('Misaine Bank SEA'); Hurley Environment, Strategic Environmental Assessment: Petroleum Exploration Activities on the Southwestern Scotian Slope (November 2011), found at: <http://www.cnsopb.ns.ca/pdfs/ SWSS_SEA_Final_Report_November_17_2011.pdf> ('Southwestern Scotian Slope SEA').

${ }^{62}$ This narrow focus is in line with the role the C-NSOPB played in these SEAs. The boards are not sufficiently impartial to be in charge of an SEA that looks at the broader policy issues. A decision to broaden the scope of the SEA would have to be matched with a realignment of responsibilities to ensure the credibility and effectiveness of the resulting SEA process.
} 
drafting and finalizing the major documents required for the process - particularly the scoping document and the SEA report.

The draft scoping document is prepared with input from expert federal authorities. It is then made available for public comment, usually for about a month. Key stakeholders with an established interest in offshore oil and gas issues, such as the fishing industries active in a given area, are contacted directly. Once all comments have been reviewed, a final scoping document is prepared and released. A similar process is used for the SEA report. The consultant prepares a draft that is released for public comment. The report is finalized once the comments received have been reviewed. ${ }^{63}$

The release of the SEA report is the final step in the process. There is no board or governmental response to the report, even though it is prepared by an outside consultant rather than by the board itself. This means that there is no clear decision from the board or the two levels of government at the conclusion of the SEA. Rather, the results of the SEA process are available to decision makers faced with whether and under what conditions to grant exploration licenses in the area. ${ }^{64}$

Our assessment of the SEAs carried out by the C-NSOPB leads to the following conclusions. First, the SEAs have generally confirmed that our understanding of the receiving environment is incomplete. Specific gaps are identified, but no specific recommendations are made on whether and how to fill these gaps, or whether the gaps should be filled before making decisions about exploration licences, exploration projects or production. Second, the SEAs have identified certain ecosystems that are either considered to be particularly valuable or sensitive to impacts from exploration activities. Examples include the area identified for the Gully Marine Protected Area and the snow crab fishing grounds in the Misaine Bank Area. Third, the SEAs have identified specific mitigation measures to protect species vulnerable to the effects of exploration activities. Examples include the impacts of noise on the endangered blue whale and the leatherback turtle.

\footnotetext{
${ }^{63}$ The most significant deviation from this process involved the Misaine Bank SEA. In this case, C-NSOPB scheduled hearings in Cape Breton to hear more directly from stakeholders concerned about exploration activities. The Misaine Bank SEA, n. 61 above, involved the most vocal opposition to exploration activities, both from aboriginal groups and from the fishing industry, concerned about the impact on the lucrative snow crab fishery in the area. The concerns were reflected in the final report and serve as a caution to developers and regulators, but no decision was made at the time of the SEA as to whether the concerns warranted excluding this area from exploration activity.

${ }^{64}$ The Southwestern Scotian Slope SEA, n. 61 above, includes a disclaimer in which the C-NSOPB disclaims any responsibility for the accuracy of the content. This is further evidence that the SEA process is exclusively an information-gathering process. It does not currently include a transparent decision-making component.
}

Fourth, cumulative effects, alternatives, worst case scenarios and broader policy issues are sometimes referenced, but no detailed analysis is carried out. The ability of exploration activity to co-exist with existing uses, particularly fishing, is included. Fifth, the conclusion reached in all SEAs is that standard mitigation is generally adequate to address any concerns about the interaction of exploration activities with the receiving environment including existing uses documented in the area, but that special mitigation identified is required in specified circumstances. Sixth, no firm decisions or recommendations are included in the SEA reports on whether, where and under what circumstances to permit exploration activity in the study area. The intent is to leave flexibility for decision makers to make regulatory decisions in light of the information provided.

In 2009, the C-NSOPB commissioned the consulting firm Griffiths Muecke to consider stakeholder consultation issues in the context of a possible regional environmental assessment for the Nova Scotia offshore area. The resulting report was based on a detailed review of the first three SEAs carried out, as well as interviews with participants and stakeholders. The Griffiths Muecke report included the following recommendations for SEAs related to offshore oil and gas exploration in Nova Scotia: an improved process for early identification of issues; a clear future-oriented perspective; identification and application of environmental protection objectives; presentation of scenarios or alternatives; a clear rationale for limiting the study to exploration and excluding consideration of development; discussion of risk and risk management; a process for risk communication; clarification of terms used to describe relative impact; clarification of the process for identifying cumulative effects; clarification of how the precautionary principle is being applied; and criteria for declaring restricted, special management or 'no-go' areas for exploration. In addition to these specific recommendations, the Griffiths Muecke report also concluded that the SEAs could have added value if they could be used: as a decision-making and planning tool for the industry, government and C-NSOPB; as a management tool for government and C-NSOPB; and as a communication tool for C-NSOPB. ${ }^{65}$

\section{EXPLORATION SEAs: NEWFOUNDLAND AND LABRADOR}

The joint SEA with Nova Scotia covering the Laurentian Sub-basin in 2003 was the C-NLOPB's first exploration SEA. ${ }^{66}$ As was the case in Nova Scotia, the C-NLOPB

\footnotetext{
${ }^{65}$ A. Muecke and L. Griffiths, 'Regional Environmental Assessment Stakeholder Consultation: Context and Issues', report submitted to C-NSOPB (December, 2009), on file with authors.

${ }^{66}$ For information about SEAs carried out by the C-NLOPB, see $<$ http://www.cnlopb.nl.ca/env_strategic.shtml>.
} 
carried out a second SEA for the Orphan Basin on its own around the same time as the joint assessment. Since then, the C-NLOPB has been more active than its counterpart in Nova Scotia, conducting SEAs on Western Newfoundland and Labrador in 2005, the Sydney Basin in 2006 and the Labrador Shelf in 2008. In 2010, the C-NLOPB carried out its first update in the form of a consolidated SEA for the southern Newfoundland offshore area.

The process followed in Newfoundland was initially identical to the Nova Scotia one described above. Over time, however, the C-NLOPB has adjusted it in a few notable ways. Key among these changes is efforts to improve public engagement and to broaden the scope of its SEAs to include some consideration of future oil and gas production scenarios. ${ }^{67}$

With respect to public engagement, the C-NLOPB has started to utilize multi-stakeholder organizing committees to broaden input into the SEA process. Notably, the 2008 assessment of the Labrador Shelf ${ }^{68}$ involved considerable efforts through a range of mechanisms to gather the views of those potentially affected by exploration and production. In particular, the Nunatsiavut government (established under the terms of the Labrador Inuit land claim agreement) engaged its citizens and fed the results into the SEA process. This allowed the Nunatsiavut government to utilize means of engagement that were culturally appropriate to its Inuit population. The Labrador Shelf SEA took the longest time - spanning close to a year.

With respect to scope, a number of SEAs carried out by the C-NLOPB provide basic information about the environmental impacts of production, suggesting that they may be taken into account when deciding whether to issue exploration licenses. Notwithstanding the inclusion of this information, the cumulative effects analysis does not include an assessment of the interaction between the effects of exploration and those from production. ${ }^{69}$ Most notably, the cumulative effects assessment has not included the development and consideration of a range of future scenarios based on different levels of oil and gas activities or other human activities in the study area.

\footnotetext{
${ }^{67}$ One notable difference in the conclusions of recent C-NLOPB SEAs are fairly detailed recommendations on how information gaps should be addressed and how findings may influence future planning and decision making.

${ }^{68}$ See Sikumiut Environmental Management, Strategic Environmental Assessment Labrador Shelf Offshore Area (August 2008), found at: <http://www.cnlopb.nl.ca/env_strategic.shtml> ('Labrador Shelf SEA').

${ }^{69} \mathrm{~A}$ good starting point, for example, could be the consideration of these interactions on particularly sensitive ecosystems and on endangered species.
}

\section{EXPLORATION SEAS: THE UNITED KINGDOM AND NORWAY}

SEAs have also been used in the offshore oil and gas context in the United Kingdom and Norway. ${ }^{70}$ This section discusses the experiences in each of these regions. A detailed review of the processes utilized in these two jurisdictions is not warranted here as they have been studied elsewhere. ${ }^{71}$ It is worth considering, however, how SEA processes in these two jurisdictions compare to those in Nova Scotia and Newfoundland, and to consider whether they offer any additional lessons for the Beaufort Sea.

In the United Kingdom, SEAs to inform decisions regarding the licensing of offshore oil and gas exploration have been carried out since 1999, although they were not legally required until 2004. They have been carried out for each of the eight offshore oil and gas quadrants. Similar to the experience on the east coast of Canada, the SEAs inform decisions at the exploration licensing stage, with project-specific EAs still required at the development stage. The scope of the SEA process, as well as its role in the decision-making process, appears reasonably similar to the experience on the east coast of Canada. ${ }^{72}$ The assessment of alternatives in the United Kingdom appears more advanced than on the east coast, but neither jurisdiction appears to be examining future scenarios as part of the SEA.

Norway appears to be conducting SEAs in a broader sense than the processes in Canada or the United Kingdom. Regional SEAs on offshore oil and gas exploration have been carried out there since 1997. More recently, since 2006, more integrated planning and assessment processes have been implemented. Most notable is the inclusion of a range of human activities in the study area, including oil and gas activity, fisheries and shipping. The end result appears to be an integrated management process that includes, but is not limited to, the impacts of oil and gas exploration. Norway thereby appears to have implemented the assessment process with the broadest scope, including alternatives and future scenario-based assessments. $^{73}$

\footnotetext{
${ }^{70}$ For an overview of SEA in the offshore oil and gas context, see C. Fidler and B. Noble, n. 5 above. See also A. Muecke and L. Griffiths, n. 65 above. The province of Quebec is also applying SEAs in two different oil and gas contexts: first with respect to possible oil and gas exploration in the marine areas of Anticosti, Madeleine and Baie des Chaleurs Basins; and second, in the context of shale gas and issues associated with hydraulic fracturing.

${ }^{71}$ See C. Fidler and B. Noble, n. 5 above.

72 Ibid.

73 lbid.
} 


\section{AN ASSESSMENT OF THE SEA PROCESS OF THE OFFSHORE BOARDS}

This section considers how the SEA processes on the Canadian east coast measures up against the nine principles of good SEA practice outlined above, and offers some thoughts on what this experience suggests for an effective and efficient SEA process for the Canadian Beaufort Sea. The first principle is that SEAs should be carried out early and proactively, and that it should operate under clear rules. The SEAs carried out by the offshore boards on the east coast are completed before any exploration projects are considered. They are initiated in conjunction with the call for bids process for the study area. Hence, SEAs follow the call for nominations process and the original decision to open an area for bids for exploration licences. While the exploration licence is issued after the SEA is completed, the linkage between the two processes is not clear. This means that even though no project decisions are made before the SEA is completed, important policy decisions do precede it. The information gathered in these SEAs contains relevant context for those earlier policy decisions. Conducting SEAs before the call for nominations would significantly enhance the efficacy of the overall decision-making process. It would also alleviate some of the time constraints under which some of them had to be carried out. Clear rules on the role of the SEA in future decision-making will also be critical to the success of an SEA for the Beaufort Sea.

The second principle is that SEAs should fully integrate ecological, social and economic issues relevant to offshore oil and gas exploration. There is limited evidence that the SEAs carried out by the offshore boards have been integrated substantively in this manner. There has been some effort to incorporate social and economic aspects related to current uses in the study areas, particularly with respect to commercial fishing and aboriginal practices. However, the SEAs fall particularly short in addressing broader policy issues, cumulative effects and alternative future development scenarios. It is here that more effort to identify the ecological, social and economic implications of choices to be made should be explored, particularly to inform the fundamental policy decision whether an area should be opened up for exploration in the first place. The experience with integrated management in Norway may offer some lessons in this regard. The main challenge in the east coast context is that broadening the scope of the SEA would make it necessary to place the process in the hands of an independent third party as the offshore boards may not be perceived as sufficiently impartial, given their focus on the oil and gas industry. Careful thought will therefore have to be given to the appropriate combination of scope and responsible party for the SEA process for the Beaufort Sea. A broad scope following the Norwegian approach with an independent panel responsible for the process would be the most effective combination.

The third principle relates to the place of SEAs among the various decision-making tiers and levels of assessment. The place of the boards' SEAs among existing information-gathering, public-engagement and decision-making processes would benefit from further clarity. There should be a clear link to early policy decisions, such as the call for nomination and the call for bids. The relationship to the issuance of the exploration licence, the approval of individual exploration activities, and the expectation of oil and gas production should also be clearly identified. The final SEA reports generally provide guidance to the boards and proponents on mitigation measures for exploration activities and areas that may be particularly sensitive to the impacts of exploration. In the process, the SEAs hint at, but do not clearly identify, areas that should be avoided. There is no formal decision at the conclusion of the SEA process. This makes it much more difficult to track the role their play in the overall decision making at other tiers and levels of assessment. There has been some effort to fill information gaps identified in the SEAs, but there has been little indication of decision makers applying a precautionary approach until the information gaps are filled. This is critically important when dealing with the exploration for oil and gas resources. The choice to explore in spite of critical information gaps increases risk and uncertainty. Careful thought will have to be given to the place of an SEA for the Beaufort Sea in the overall decision-making process for offshore oil and gas exploration and development in the study area. It will be important to be clear about its role before the start of the SEA process. SEA experiences in the United Kingdom and Norway may offer more insights here than the east coast experience as there are more examples of follow-up development decisions in areas subject to SEAs.

The fourth principle relates to the legal context within which SEAs are carried out. They are not required by the legislation which establishes either of the two boards. The purpose, terms of reference and scope of the process is not set out in laws, regulations or policy guidance. There is no opportunity for appeal where SEA principles or prescribed requirements seem not to have been satisfied, and there are no procedures for monitoring, reviewing, iterative learning and identification of needs for corrective action and implementation. The responsibilities of the board, governments, industry and other stakeholders are also not clearly defined through legal or policy documents. In short, both boards have proactively made a decision to conduct SEAs, but these decisions have not yet been supported by legislative change, regulations or even formal policy guidance. Two things have happened to provide some legal context: the SEAs have been brought under the 
federal cabinet directive on SEA $;{ }^{74}$ and SEA reports in Newfoundland have started to make a link to the legislative mandate of the board by pointing out the role of the board in ensuring oil and gas activities are carried out in an environmentally responsible manner. ${ }^{75}$

In theory, the lack of legal context should make the process very flexible, which brings us to the fifth principle. The benefit of this flexibility is that there is room for learning by doing before the process is enshrined in law. In practice, however, the adjustments to the processes in Nova Scotia and Newfoundland-Labrador have been modest to date. The only discernible trend is that SEAs executed in Newfoundland-Labrador have made more of an effort to engage interested parties and the general public. ${ }^{76}$ Ideally, the context for an SEA process for the Beaufort Sea would be enshrined in appropriate legislation, regulations and policies. At an experimental stage, a clear policy statement can at times be an adequate substitute so long as there is a clear political commitment to the process, and provided that the policy is enshrined in law as it moves on from its experimental beginnings.

The sixth principle relates to public engagement and transparency. Public participation has generally been low in SEAs carried out by the C-NSOPB. The SEA process has focused on engaging a few organizations proactively. Key stakeholders and broader interested public interest are invited to comment on the scoping document and the final SEA report, but not enough proactive steps are taken to encourage their direct participation in the process. ${ }^{77}$ Access to information has been limited to draft and final reports and to submissions from other participants. Opportunities to submit views were in many cases limited to written submissions with short timelines. No resources were made available to those potentially affected to understand the issues and participate, but there are preliminary signs that opportunities for increased input have been matched with cultural preferences. ${ }^{78}$ Public engagement is one of the most critical areas to build on when looking at the experience on the east coast. More time and resources will have to be made available, but careful consideration also needs to be given to other factors, such as the credibility of the process and clear understanding of its role in decision making on offshore oil and gas activity in the Beaufort Sea.

The seventh principle refers to the motivation of participants to learn from the SEA process and use it as a

\footnotetext{
74 Ibid.

${ }^{75}$ See Labrador Shelf SEA, n. 68 above, at 1.

76 lbid.

${ }^{77}$ Among the factors that influence public participation are awareness, adequate time and resources, easy access to information, familiarity with SEA and a clear understanding of its role in the overall governance process as well as trust in the process.

${ }^{78}$ See Misaine Bank SEA, n. 61 above; Labrador Shelf SEA, n. 68 above.

basis for decision making. The SEAs carried out by the boards have so far been about information gathering, without any clear recommendations in the SEA or direct decisions based on it. ${ }^{79}$ As a result, it is difficult to comment on whether there are effective incentives in place, or whether participants are motivated to learn from the results of the process. Similarly, without clear recommendations on what should happen as a result of the SEAs, it is difficult to track performance. This issue requires careful consideration in the design of an SEA process for the Beaufort Sea, and the east coast experience offers little guidance in this regard.

The eighth principle relates to follow-up. Given the lack of recommendations and decisions, it is not surprising that there are no requirements for follow-up and monitoring of the implementation of the SEA as there are no clear decisions or recommendations to implement. The decision making takes place at the exploration project level. Neither of the two boards has used SEAs to make broad policy decisions. Both boards have made an informal commitment to update SEAs if there is any activity in the area more than five years after the initial SEA. Any SEA process for the Beaufort Sea will have to give careful consideration to the allocation of responsibility to ensure effective monitoring and follow-up, including full transparency and effective response as problems are identified. The experience on the east coast offers no guidance on this issue.

The ninth principle refers to the political commitment to implement an effective SEA process and to utilize its results. Given the somewhat tentative nature of the SEA process on the east coast to date, and limited time and resources allocated to them, it is difficult to escape the conclusion that there is no significant political commitment to the process. It appears to be a process held together by staff at the boards, mainly because it takes limited resources and time to complete, it simplifies project-specific EAs, and it does little to constrain decision makers. It is clear from the east coast experience that political commitment is critical for the effectiveness of any SEA. The SEA process for the Beaufort Sea therefore cannot be designed and implemented in isolation from the effort to gain political commitment. On the one hand, there is no point in gaining political commitment for an SEA process that is ineffective, inefficient or unfair. On the other hand, there is no point in designing an effective, efficient and fair process in line with the first eight principles if there is no political commitment to follow through. A big part of this will be a shared understanding of the value of an effective SEA process in improving the quality and efficiency of future decisions regarding offshore oil and gas exploration and development in the region.

\footnotetext{
${ }^{79}$ Of course, the boards would be expected to consider the information in deciding whether or not to issue exploration licences.
} 


\section{CONCLUDING REMARKS: APPLICATION OF SEAS TO THE BEAUFORT SEA}

This section offers some concluding thoughts on why and how to integrate an SEA process into decisions about oil and gas exploration in offshore areas in Northern Canada including the Beaufort Sea. ${ }^{80}$ We have argued, consistent with the federal cabinet directive, the Arctic Council guidelines, the Kiev Protocol and the current practice of the C-NSOPB and C-NLOPB, that governments in the Arctic should integrate SEAs into the oil and gas exploration and rights issuance procedures in advance of issuing a call for nominations. A well-designed SEA is the most effective and efficient tool available to ensure an appropriate policy context for development, the proper consideration of alternatives and to provide the necessary basis for cumulative effects assessments at the project level. SEAs can also be critical tools in engaging those potentially affected by development to work toward a common vision. Ultimately, it is important that governments take decisions as to whether to grant oil and gas rights in a particular area rather than simply following industry's lead. Governments need to make those decisions on an informed basis in the long-term best interest of society.

The current legislation in Canada is flexible enough to allow the Minister to require that an SEA be conducted. We propose that the SEA be conducted before a call for nominations and a call for bids. This proposed timing addresses the first principle to the effect that the SEA should be applied early and proactively. The Minister might also retain the discretion to conduct additional SEAs outside the rights issuance process to address scientific or spec seismic operations. We envisage that this would be a rare situation, but in some cases seismic operations may pose strategic questions as well as the project-specific questions that would be addressed through a CEAA screening or other review.

There are several possible ways in which to address principles 2-5, including amendments to the CPRA, and possibly to regulations, but neither approach is necessary. Instead, just as the offshore boards have developed guidance notes and similar documents, including one relating to declarations of significant discovery, we think that it should be possible to follow a similar approach here and develop a guidance document for 'exploration SEAs'. This document would address a number of matters including the scope of the SEA (incorporating ecological, biophysical and socioeconomic issues) and the questions that the SEA should address, including identification of information deficiencies and the linkages with other tiers of assessment.

${ }^{80}$ The scheme described here should apply to all lands covered by the CPRA, but the primary focus of this article is the Beaufort Sea.
The document would be sufficiently open-ended to provide the flexibility to tailor it to the particular circumstances of the case.

As noted in the previous section, as parties obtain experience with SEAs, it might be appropriate to provide a more formal legal foundation for the process in oil and gas dispositions. We anticipate that the Minister would have to take the lead in developing this document (as the responsible party under the CPRA), but in doing so the Minister would need to draw on the expertise of others (including the NEB and the Canadian Environmental Assessment Agency), and closely consult with the relevant institutions established by the land claim agreements. These institutions would include relevant bodies established by the Inuvialuit Final Agreement and Nunavut Land Claims Agreement. Including these institutions at the outset would help to establish the relevant linkages between the SEA and other tiers of assessment including not only project-specific environmental assessments, but also land use planning procedures.

Such a guidance document for exploration SEAs would also need to identify the entity that should be responsible for its conduct. We have noted that there are some problems associated with having a body (like the offshore boards) with the responsibility for regulating oil and gas exploration also assume responsibility for the SEA. In the Beaufort Sea, the possible lead agencies would include the Minister, the NEB or a relevant entity established by a land claim agreement. The selection of an entity other than the Minister or Department would help establish the credibility and integrity of the process. It will also be important to identify those parties who will use the resulting SEAs and for what purpose. These might include the following:

- The Minister may use the SEA to decide whether to issue a call for nominations and to inform the configuration of bidding blocks and the minimum terms and conditions to be included in the bidding documents.

- The NEB may use the SEA in issuing authorizations under COGOA and establishing appropriate terms and conditions for those authorizations.

- Institutions established by land claim agreements, including those bodies with responsibilities for land use planning and screening and project assessment, may also use the SEA report in discharging their responsibilities under the terms of the land claim agreement and any implementing legislation.

These issues are clearly related to, and overlap with, the third principle that deals with tiers of assessments.

The sixth principle addresses the importance of transparency and public involvement in the process. Our assessment of the experience with the offshore boards 
suggests that this has been a weak area in the practice of the boards and that the party responsible for the SEA will need to be proactive. It is typically more difficult to engage the public in a strategic assessment than in a project-specific assessment. This issue also needs to be covered in the proposed guidance document. The timing issues might be resolved by decoupling the SEA from the timelines established by the call for bids process but it will be important that the guidance document address the funding for informed community involvement.

Principles 7-9 deal with incentives, follow-up and political commitment. The principal incentive for engaging in high quality SEAs might be stated in several ways. First, adoption of SEAs as standard practice is consistent with the recommendations of the Arctic Council ${ }^{81}$ of which Canada is a member. It is also consistent with the requirements of the federal cabinet directive. Indeed, it is not clear to us how the Minister has managed to avoid conducting SEAs. ${ }^{82}$ Second, the SEA procedure is consistent with the Crown's obligations under the terms of relevant land claim agreements as well as any freestanding constitutional obligation to consult (and accommodate) aboriginal peoples in relation to proposed decisions that may affect their rights and interests. ${ }^{83}$ Establishing clear procedures for when and how SEAs will be implemented will provide a degree of legal certainty for all parties, including government and industry, and help meet the Crown's constitutional obligations.

Requirements for follow-up might also be prescribed in the proposed exploration SEA guidance document. The guidance will need to identify the parties responsible for drawing up the list of those whose decisions will be informed by the SEA. The principal evidence of political commitment to the process will be the development of the guidance document (or amendments to the CPRA or new regulations) as well as the actual use of the resulting SEAs in decision making. Other evidence will be a commitment to involve local communities in the process. This will demonstrate that SEAs are not being conducted simply to tick a box, but to inform subsequent decision making. ${ }^{84}$

\footnotetext{
${ }^{81}$ See Arctic Council, n. 8 above.

82 It is important to emphasize that we are not suggesting that compliance with the federal cabinet directive is adequate since we base our evaluation of the adequacy of an SEA process on the nine principles distilled from the literature, rather than the formal requirements of the directive.

${ }^{83}$ Beckman, n. 35 above.

${ }^{84}$ We might borrow here the phrase 'demonstrably integrated', which comes from some of the aboriginal consultation cases. See Halfway River First Nation v. British Columbia (Ministry of Forests) (1999), BCCA 470; West Moberly First Nations v. British Columbia (2011), BCCA 247. Using this as a test it will be up to government through policy statements, press releases and specific decisions to demonstrate how it is taking into account and using the results of the SEA.

The current procedure of the east coast boards is ad hoc in the sense that it is not enshrined in legislation or regulations, which leads directly to some of the shortcomings that we have identified. We think that a key step in addressing many of these issues lies in the development of an appropriate guidance document. Such a document would have to be developed collaboratively with the relevant institutions of the land claim agreement if it were to have any credibility and legitimacy and to allow SEAs to contribute to appropriate tiered decision making.

In conclusion, we reiterate that the SEA process proposed here would draw on much of the valuable work that has been ongoing in the Beaufort Sea over a number of years under the auspices of the Beaufort Sea Strategic Regional Plan of Action, a joint federalInuvialuit-industry oil and gas planning process, and the proposed Beaufort Regional Environmental Assessment, which will be launched in 2012 for a five-year term. This project should contribute to the quality of the SEAs anticipated by this article since it will, inter alia, identify and address data gaps and generate regional scale scientific and socioeconomic information that can be fed in to the SEA, but it does not replace the need for the SEA.

More broadly, legislated SEAs along the lines outlined here should become a standard part of any regulatory regime for offshore oil and gas exploration in the broader Arctic region and beyond. The experience on the east coast shows the potential value, but also the limitations of an ad hoc process with a limited mandate and resources. A well-implemented SEA process at the early stages would significantly enhance decision making in the offshore oil and gas sector.

Meinhard Doelle is a Professor of Law at the Schulich School of Law, Dalhousie University. He currently serves as the Director of the Marine and Environmental Law Institute and the Associate Dean, Research. His research interests include environmental impact assessments, climate change and energy governance. He has served as an advisor on strategic environmental assessments in Canada, including the 2008 SEA on tidal energy in the Bay of Fundy, Nova Scotia.

Nigel Bankes is a Professor of Law at the University of Calgary, where he holds the chair in natural resources law, and an adjunct professor of law at the University of Tromsø.

Louie Porta holds a Masters degree from Dalhousie University's School for Resource and Environmental Studies and currently is a Science and Policy Advisor for Oceans North Canada. He has worked with and for the Inuvialuit, Gwich'in, Inupiat, Mi'kmaq and the Government of Canada. 